\title{
Biogen wins Euro MS approval, but loses patents
}

The battle for multiple sclerosis markets heated up in early April; not only did Teva (Israel) launch Copaxone (formerly copolymer-1, now glatiramer acetate) in the US, but Biogen's (Cambridge, MA) Avonex (interferon $\beta$-1a) received approval from the European Medicine Evaluation Agency (EMEA; London). But as Nature Biotechnolo$g y$ went to press, the European Patent Office (EPO; Munich) revoked Biogen's European patent on the production of $\beta$-interferon in mammalian cells and bacteria, a decision that cannot be appealed.

After issuing the patent in 1990, the EPO has now ruled that it is not valid because the work described in it was obvious and therefore lacked the inventive step. The patent was based on research of Walter Fiers of the University of Ghent (Belgium). Fiers was a cofounder of Biogen.

\section{nature}

biotechnology

\section{gives you more information about advances in industrial biology than any other source.}

\author{
In each monthly issue, \\ Nature Biotechnology covers the \\ latest research and applications that \\ drive biotechnological innovation in:
}

- biotechnology

- pharmaceuticals

- chemicals

- agricultural

- veterinary medicine

- the environment

- energy

- natural products industries

\section{Start your subscriptions today!}

For more information, please contact Nature Biotechnology at:

$$
\text { 1-800-524-0328 (U.S. only) }
$$

1-615-377-3322 (in Canada and Mexico)

Biogen's president and CEO Jim Tobin said that the EPO decision would have "no effect" on the company's ability to sell Avonex in Europe. But Biogen will lose any royalty revenues that it might have expected from other company's $\beta$-interferon sales in Europe.

Schering (Berlin), which had brought the patent action against Biogen, had announced in mid-March that it expected sales of its Betaseron (interferon $\beta$ - $1 \mathrm{~b}$ ) -the first multiple sclerosis drug to reach the market-to rise over $10 \%$ this year, to over $\$ 350$ million. At that time, analyst Peter Drake of Vector Securities (Deerfield, IL) had predicted that Biogen's earnings would exceed an earlier estimate of $\$ 1.37$ per share by eight cents, and that its share price could rise to $\$ 57$ (compared to $\$ 40.50$ at the end of March). Analysts marked Biogen down only slightly on the recent patent news.

Meanwhile, another analyst, Jerry Treppel from Dillon Read (New York), predicted that the first-year sales of Teva's Copaxone would be $\$ 100$ million, with a potential of $\$ 200-300$ million. But in mid-March, Teva's share price fell $\$ 10$ to $\$ 54$. Treppel attributed this to rumors in an equity report on Biogen published by a rival brokerage, that an order from the US Food and Drug Administration (Rockville, MD) asking Teva to remove data on the use of Copaxone in progression of multiple sclerosis would delay the drug's launch. Copaxone was approved for reducing the relapse rate of patients with the remitting/relapsing form of multiple sclerosis. Treppel says that the offending information had actually been removed over six months ago. However, data still included with the drug suggest that Copaxone affects the "accumulation of disability," a phrase that could be interpreted as implying efficacy against the disease's progression. Other analysts besides Treppel believe that an improved side-effect profile and unique mechanism of action will mean that Copaxone can compete in a multiple sclerosis market that is becoming increasingly crowded.

Two other $\beta$-interferon drugs, AresSerono's (Geneva) Rebif (recombinant interferon $\beta-1 \mathrm{a}$ ), and Frone, (interferon $\beta-1 b$ ), completed phase III trials last summer. They reduced the relapse rate in relapsing/remitting disease $60 \%$ and $52 \%$, respectively, but, as with Schering's and Biogen's drugs, patients frequently experience flu-like symptoms and irritation at the injection site. In two trials, Copaxone reduced relapses $29 \%$ and $75 \%$, compared with placebo, without flu-like symptoms, depression, or fatigue. Patients do commonly experience injection site reactions, flushing, and transient chest tightness, however.

Vicki Brower 